\title{
Pain of methadone-maintained heroin addicts: lonelier individuals feel more intense pain
}

\author{
Fu Li ${ }^{1}$, Yan-Min Xu ${ }^{1}$, Jun-Hong Zhu ${ }^{1}$, Jin Lu ${ }^{2}$ and Bao-Liang Zhong ${ }^{1}$ \\ ${ }^{1}$ Affiliated Wuhan Mental Health Center (The Ninth Clinical School), Tongji Medical College of Huazhong University of Science \\ and Technology, Wuhan, Hubei Province, China \\ ${ }^{2}$ Department of Psychiatry, The First Affiliated Hospital of Kunming Medical University, Kunming, Yunnan Province, China \\ Correspondence to: Jin Lu, email: jinlu2000@163.com \\ Bao-Liang Zhong, email: haizhilan@gmail.com
}

Keywords: pain, loneliness, heroin addiction, methadone

Received: June 10, 2017 Accepted: August 06, $2017 \quad$ Published: August 22, 2017

Copyright: Li et al. This is an open-access article distributed under the terms of the Creative Commons Attribution License 3.0 (CC BY 3.0), which permits unrestricted use, distribution, and reproduction in any medium, provided the original author and source are credited.

\section{ABSTRACT}

Managing pain in patients with heroin addiction is challenging, because most pain medications are addictive. A promising way to relieve pain of heroin addicts is to identify and address modifiable psychosocial factors associated with pain. This study examined the association between loneliness and pain intensity in Chinese heroin addicts receiving methadone maintenance treatment (MMT). A consecutive sample of 603 heroin addicts were recruited from three MMT clinics in Wuhan, China. Loneliness was assessed with a single question, and socio-demographic and clinical data were collected with a standardized questionnaire. Pain intensity was assessed with the five-point Verbal Rating Scale. Multiple ordinary logistic regression was used to control for potential confounders that may bias the loneliness-pain relationship. There was a significant and positive correlation between pain intensity and loneliness scores among methadone-maintained heroin addicts $(r=0.453, P<0.001)$. After controlling for potential socio-demographic and clinical confounders, an increase in the level of loneliness was significantly associated with an increase in pain intensity $(O R=1.22, P=0.042)$. Loneliness is significantly associated with pain of methadonemaintained heroin addicts. Psychosocial interventions aimed at reducing loneliness might prevent or reduce pain of patients receiving MMT.

\section{INTRODUCTION}

Pain is a common health issue in patients with opioid use disorders [1,2]. In China, studies have found a $39.7 \%$ prevalence of chronic severe pain in heroin addicts from compulsory detoxification centers and a $14.1 \%$ prevalence of clinically significant pain in heroin addicts from methadone maintenance treatment (MMT) clinics [3, 4]. The presence of pain is significantly associated with reduced quality of life, poor response to MMT for opioid dependence, and opioid addiction relapse of heroin addicts $[3,5,6]$. Therefore, effective pain management is very important in addiction treatment practice. However, managing pain in heroin addicts is particularly challenging, because most pain medications are addictive [7].

In China, due to institutional exclusion and social stigma towards individuals with heroin addiction, heroin addicts often have poor social support networks and are socially isolated $[8,9]$. Because social isolated persons are more likely to feel lonely $[10,11]$, loneliness might be a prevalent psychosocial problem in heroin addicts.

Psychosocial factors also play an important role in the etiology, clinical course, and prognosis of pain [12]. Studies with samples of adolescents, cancer survivors, caregivers of dementia patients, and fibromyalgia patients have consistently reported loneliness as a significant predictor of pain [13-15]. Evidence from systematic reviews shows that loneliness can be relieved by a range of interventions [16, 17]. Therefore, identifying and addressing modifiable psychosocial factors associated with pain such as loneliness, would be a promising way to reduce pain and its associated negative outcomes. However, in heroin addicts, it is unclear that whether loneliness is significantly associated with their pain. 
China has the largest population of drug users globally. In 2004, China initiated its MMT program, which, until now, has been the largest MMT program in the world $[18,19]$. By 2014, there had been a total of 765 community-based MMT clinics providing services to 0.19 million illicit drug (mainly heroin) users in 28 provinces of the mainland China [20]. Given the lack of empirical studies on loneliness-pain link in heroin addicts and the quite large number of methadone-maintained patients in China, the present study examined the association between loneliness and pain intensity in Chinese heroin addicts of MMT clinics.

\section{RESULTS}

In total, 603 patients completed the survey. The average age of the 603 patients was 38.1 years (standard deviation $[\mathrm{SD}]=7.0$ ), and $68.3 \%$ were males. Scores of Zung's Self-rating Depression Scale (SDS) and Zung's Self-rating Anxiety Scale (SAS) were 38.6 (SD = 8.4) and $44.8(\mathrm{SD}=9.6)$, respectively. Detailed socio-demographic and clinical characteristics of the study participants are displayed in Table 1.

Scores of loneliness and pain intensity score of methadone-maintained heroin addicts were $2.9(\mathrm{SD}=1.0)$ and $2.8(\mathrm{SD}=1.1)$, respectively. Loneliness and pain intensity were significantly and positively correlated $(r=0.453, P<0.001)$.

After controlling for the confounding effects of socio-demographic and clinical variables with multiple ordinary logistic regression, an increase in the level of loneliness was significantly associated with an increase in pain intensity $(\mathrm{OR}=1.22, P=0.042)$.

\section{DISCUSSION}

Heroin addiction is not only a medical issue but also a social issue, thus the clinical management of any health problem in heroin addicts should take psychosocial factors into consideration. The present study determined the relationship between loneliness and pain in patients of MMT clinics, and found a statistically significant moderate, positive correlation between the level of loneliness and pain intensity. After controlling for the potential confounding effects of other covariates, loneliness remained significantly associated with pain, suggesting an independent effect of loneliness on pain in heroin addicts.

Most existing studies on the health consequences of loneliness focused on middle-aged and older adults, showing the significant contribution of loneliness to increased mortality, metabolic syndrome, depression, and reduced cognitive functions of this population [10, 21-23]. Findings from our study suggest that loneliness is also a significant contributor to increased pain intensity. Pain is conceived as not only an unpleasant sensory but also an emotional state, so the complex process of pain is subject to a variety of psychosocial factors $[24,25]$. For example, the study by Wolf and colleagues found lonely episodes were associated with subsequent increases in negative thinking about pain, which in turn exemplified the perception on pain intensity of a stimulus [15]. Therefore, the significant loneliness-pain link revealed in this study may be explained by the increased negative cognition on pain resulted from loneliness. In addition, loneliness (in particular chronic loneliness) can suppress the functions of the immune system, making lonely individuals susceptible to a high inflammation status [26]. There is evidence that pain or hyperpathia can be caused by a variety of bioactive compounds released by inflammatory cells such as neurokinin, bradykinin, histamine, and inflammatory cytokines [27]. This is another possible biological mechanism underlying the loneliness-pain association.

This study has a few limitations. First, data of this study were collected cross-sectionally, which limits the ability to make causal inference on the loneliness-pain relationship. Second, due to deficiencies in the study design, we did not collect data on possible inflammatory cytokines and other bioactive compounds to explore the biological mechanism of how loneliness impacts pain. Third, due to the stigma associated with loneliness, the direct measure of loneliness used in this study, the singleitem question, may result in an underestimate of the actual prevalence of loneliness [28]. As a result of this, our study might underestimate the loneliness-pain association.

Despite the limitations of the study, this study reveals that loneliness is significantly associated with pain in Chinese heroin addicts of MMT clinics. The research results suggest that providing psychosocial interventions such as those enhancing social support and addressing maladaptive social cognition [16] cannot only reduce loneliness, but also potentially reduce the pain of patients in MMT clinics.

\section{MATERIALS AND METHODS}

\section{Subjects}

This is a secondary data analysis based on a crosssectional survey conducted in three city-owned MMT clinics in Wuhan, China, between June 2009 and July $2010[3,29,30]$. The study consecutively enrolled 652 adult heroin addicts who met DSM-IV criteria for a lifetime diagnosis of heroin addiction. Patients with severe physical diseases, alcohol dependence, organic mental disorders, or psychotic symptoms, were excluded from the survey.

The Ethics Committee of Wuhan Mental Health Center approved the study protocol prior to the formal study. All participants provided written informed consent. 
Table 1: Multiple ordinal logistic regression analysis on the effect of loneliness on pain intensity

\begin{tabular}{|c|c|c|c|c|c|c|c|}
\hline \multirow[b]{2}{*}{ Variable } & & \multirow[b]{2}{*}{$n$} & \multicolumn{5}{|c|}{ Pain Intensity Score } \\
\hline & & & $\begin{array}{c}\text { Standardized } \\
\text { Coefficient }\end{array}$ & $\begin{array}{l}\text { Standard } \\
\text { Error }\end{array}$ & Wald $\chi^{2}$ & OR $(95 \%$ CI $)$ & $P$ \\
\hline Loneliness score & & 603 & 0.196 & 0.097 & 4.14 & $1.22(1.01,1.47)$ & 0.042 \\
\hline \multirow[t]{2}{*}{ Gender } & Male & 412 & 0.045 & 0.188 & 0.057 & $1.05(0.72,1.51)$ & 0.812 \\
\hline & Female & 191 & 1 & & & & \\
\hline \multirow[t]{2}{*}{ Age(year)\# } & $<39$ & 300 & -0.071 & 0.192 & 0.137 & $0.93(0.64,1.36)$ & 0.712 \\
\hline & $\geq 39$ & 303 & 1 & & & & \\
\hline \multirow[t]{2}{*}{ Length of Education\# } & $<9$ & 140 & -0.785 & 0.209 & 14.129 & $0.46(0.30,0.69)$ & $<0.001$ \\
\hline & $\geq 9$ & 463 & 1 & & & & \\
\hline \multirow[t]{3}{*}{ Marital Status } & Never-married & 154 & 0.324 & 0.215 & 2.26 & $1.38(0.91,2.11)$ & 0.133 \\
\hline & Others* & 154 & 0.154 & 0.235 & 0.431 & $1.17(0.74,1.85)$ & 0.512 \\
\hline & Married & 295 & 1 & & & & \\
\hline \multirow[t]{2}{*}{ Route of past heroin use } & Injection & 507 & 0.003 & 0.233 & 0.001 & $1.00(0.64,1.58)$ & 0.991 \\
\hline & Smoking & 96 & 1 & & & & \\
\hline \multirow[t]{2}{*}{ Duration of past heroin use (year)\# } & $<10$ & 230 & -0.237 & 0.181 & 1.721 & $0.79(0.55,1.12)$ & 0.190 \\
\hline & $\geq 10$ & 373 & 1 & & & & \\
\hline \multirow[t]{2}{*}{ MMT dose (mg/d)\# } & $<70$ & 273 & -0.324 & 0.178 & 3.318 & $0.72(0.51,1.03)$ & 0.069 \\
\hline & $\geq 70$ & 330 & 1 & & & & \\
\hline \multirow{2}{*}{ MMT duration (months)\# } & $<24$ & 240 & 0.578 & 0.185 & 9.811 & $1.78(1.24,2.56)$ & 0.002 \\
\hline & $\geq 24$ & 363 & 1 & & & & \\
\hline \multirow[t]{2}{*}{ Depressive symptoms } & Yes & 204 & 0.939 & 0.212 & 19.659 & $2.56(1.69,3.87)$ & $<0.001$ \\
\hline & No & 399 & 1 & & & & \\
\hline \multirow[t]{2}{*}{ Anxiety symptoms } & Yes & 219 & 1.404 & 0.246 & 15.454 & $4.07(2.51,6.59)$ & $<0.001$ \\
\hline & No & 384 & 1 & & & & \\
\hline
\end{tabular}

\#Continuous variables were dichotomized via the median split procedure.

*Others include remarried, divorced, separated, and widowed.

\section{Procedures and assessments}

This study was a self-administered questionnaire survey. Trained psychiatrists working in MMT clinics were arranged to read out questions for subjects who were illiterate or had difficulties in reading. Before the collection of these questionnaires, our investigators checked the completeness and coherence of responses to questions in the questionnaire.

A questionnaire was specifically designed for this study. Because previous population-based studies have reported a significant associations between sociodemographic factors, particularly low socio-economic status (as measured by education and income), and pain [31-33], socio-demographic variables in the questionnaire included gender, age, education years, marital status, employment status, and self-rated financial status (good, fair, poor). Because substance use characteristics (i.e., long-term heroin use and injection drug use) and psychological factors have been found to be significantly associated with pain [34-36], clinical data collected in the study were usual route of past heroin administration (smoking, injecting), duration of past heroin use, duration of MMT, methadone dosage, depression, and anxiety.
Depression and anxiety were assessed with SDS and SAS, respectively [37]. The total scores of both SDS and SAS vary between 20 and 80, and a cut-off scores of 40 or higher in Chinese SDS and 43 or higher in Chinese SAS are used to denote clinically significant depressive and anxiety symptoms, respectively [37].

Loneliness was measured with a single-item selfreport question "How often do you feel lonely?" with a five-point scale: $1=$ never, $2=$ seldom, $3=$ sometimes, $4=$ often, $5=$ always. This single-item measure of loneliness is widely used in previous studies and it has good validity in assessing the level of loneliness [10, 11, 28, 38-43]. Compared multi-item loneliness scales (i.e., the UCLA Loneliness Scale), this single-item measure of loneliness is time-saving and can reduce subjects' response burden, which are particularly suitable for subjects with low level of educational attainment. Importantly, this single item does avoid potential confounding that might stem from multi-item loneliness measures [10], for example, the UCLA Loneliness Scale uses social support to represent loneliness indirectly.

Pain intensity was assessed with the five-point Verbal Rating Scale (VRS), asking "Overall, how intense is your pain now?", with a five-category responses: 
$1=$ none, $2=$ mild, $3=$ moderate, $4=$ severe, $5=$ very severe. This five-point VRS measure of pain has been widely adopted in prior studies and studies have shown that its validity was as good as other common measures of pain intensity $[44,45]$.

\section{Statistical analysis}

Loneliness and pain intensity scores of heroin addicts were described, and Pearson Correlation Coefficient was used to measure the strength of the association between the two. The impact of loneliness on pain was examined with multiple ordinary logistic regression that entered pain intensity score as the outcome variable, loneliness score as the predictor, and socio-demographic and clinical covariates at once to adjust for the potential confounding effects of these socio-demographic and clinical variables. The statistical significance level was set at $p<0.05$ (twosided). SPSS software version 20.0 package was used for analyses.

\section{ACKNOWLEDGMENTS}

The authors thank all the patients involved in this study for their cooperation and support.

\section{CONFLICTS OF INTEREST}

The authors declare no conflicts of interest.

\section{GRANT SUPPORT}

This study was supported by Wuhan Health and Family Planning Commission [WG16A02, BL Zhong, PI] and Health and Family Planning Commission of Yunnan Province [2016NS027, J Lu, PI].

\section{REFERENCES}

1. Hsera YI, Mooneya LJ, Saxonb AJ, Miottoa K, Bella DS, Huanga D. Chronic pain among patients with opioid use disorder: Results from electronic health records data. J Subst Abuse Treat. 2017; 77:26-30.

2. Rosenblum A, Joseph H, Fong C, Kipnis S, Cleland C, Portenoy RK. Prevalence and characteristics of chronic pain among chemically dependent patients in methadone maintenance and residential treatment facilities. JAMA. 2003; 289:2370-2378.

3. Liu Y, Zhong BL, Zhu JH. Pain and its association with quality of life in heroin-dependent patients receiving methadone maintenance treatment. Chin J Pain Med. 2017; 23:44-48.

4. Gao YJ, Wang LN, Qu HR, Xu QY, Kong YB, Zhang $\mathrm{BH}$, Zhang W. Prevalence and characteristics of chronic severe pain among heroin addicts from compulsory drug rehabilitation centers. Chin J Pain Med. 2016; 22:523-526.

5. Dennis BB, Bawor M, Paul J, Plater C, Pare G, Worster A, Varenbut M, Daiter J, Marsh DC, Desai D, Thabane L, Samaan Z. Pain and Opioid Addiction: A Systematic Review and Evaluation of Pain Measurement in Patients with Opioid Dependence on Methadone Maintenance Treatment. Curr Drug Abuse Rev. 2016; 9:49-60.

6. Noormohammadi MR, Nikfarjam M, Deris F, Parvin N. Spiritual Well-Being and Associated Factors with Relapse in Opioid Addicts. J Clin Diagn Res. 2017; 11:VC07-VC10.

7. Oliver J, Coggins C, Compton P, Hagan S, Matteliano D, Stanton M, St Marie B, Strobbe S, Turner HN. American Society for Pain Management nursing position statement: pain management in patients with substance use disorders. Pain Manag Nurs. 2012; 13:169-183.

8. Lembke A, Zhang N. A qualitative study of treatmentseeking heroin users in contemporary China. Addict Sci Clin Pract. 2015; 10:23.

9. Lin SZ. Institutional Exclusion and Social Acceptance: Dilemma and Outlet for Heroin Addicts to Return to Society. Guizhou Soc Sci. 2015; 305:48-52.

10. Zhong BL, Chen SL, Tu X, Conwell Y. Loneliness and Cognitive Function in Older Adults: Findings From the Chinese Longitudinal Healthy Longevity Survey. J Gerontol B Psychol Sci Soc Sci. 2017; 72:120-128.

11. Zhong BL, Chen SL, Conwell Y. Effects of Transient Versus Chronic Loneliness on Cognitive Function in Older Adults: Findings From the Chinese Longitudinal Healthy Longevity Survey. Am J Geriatr Psychiatry. 2016; 24:389-398.

12. Gupta A, Silman AJ, Ray D, Morriss R, Dickens C, MacFarlane GJ, Chiu YH, Nicholl B, McBeth J. The role of psychosocial factors in predicting the onset of chronic widespread pain: results from a prospective populationbased study. Rheumatology. 2007; 46:666-671.

13. Stickley A, Koyanagi A, Koposov R, Blatny M, Hrdlicka M, Schwab-Stone M, Ruchkin V. Loneliness and its association with psychological and somatic health problems among Czech, Russian and U.S. adolescents. BMC Psychiatry. 2016; 16:128.

14. Jaremka LM, Andridge RR, Fagundes CP, Alfano CM, Povoski SP, Lipari AM, Agnese DM, Arnold MW, Farrar WB, Yee LD, Carson WE 3rd, Bekaii-Saab T, et al. Pain, depression, and fatigue: loneliness as a longitudinal risk factor. Health Psychol. 2014; 33:948-957.

15. Wolf LD, Davis MC, Yeung EW, Tennen HA. The withinday relation between lonely episodes and subsequent clinical pain in individuals with fibromyalgia: Mediating role of pain cognitions. J Psychosom Res. 2015; 79:202-206.

16. Masi CM, Chen HY, Hawkley LC, Cacioppo JT. A metaanalysis of interventions to reduce loneliness. Pers Soc Psychol Rev. 2011; 15:219-266.

17. Gardiner C, Geldenhuys G, Gott M. Interventions to reduce social isolation and loneliness among 
older people: an integrative review. Health Soc Care Community. 2016.

18. Sullivan SG, Wu Z, Rou K, Pang L, Luo W, Wang C, Cao X, Yin W, Liu E, Mi G, National Methadone Maintenance Treatment Working Group. Who uses methadone services in China? Monitoring the world's largest methadone programme. Addiction. 2015; 110:29-39.

19. Zhao Y, Shi CX, McGoogan JM, Rou K, Zhang F, Wu Z. Methadone maintenance treatment and mortality in HIVpositive people who inject opioids in China. Bull World Health Organ. 2013; 91:93-101.

20. Huang YM. Progress and challenges of methadone maintenance treatment in China. J Applied Prev Med. 2015; 21:63-65.

21. Hawkley LC, Thisted RA, Masi CM, Cacioppo JT. Loneliness predicts increased blood pressure: 5-year crosslagged analyses in middle-aged and older adults. Psychol Aging. 2010; 25:132-141.

22. Cacioppo JT, Hawkley LC, Thisted RA. Perceived social isolation makes me sad: 5-year cross-lagged analyses of loneliness and depressive symptomatology in the Chicago Health, Aging, and Social Relations Study. Psychol Aging. 2010; 25:453-463.

23. Zhong BL, Liu TB, Chan SS, Jin D, Hu CY, Dai J, Chiu HF. Common mental health problems in rural-to-urban migrant workers in Shenzhen, China: prevalence and risk factors. Epidemiol Psychiatr Sci. 2017:1-10.

24. Peacock S, Patel S. Cultural Influences on Pain. Rev Pain. 2008; 1:6-9.

25. Simons LE, Elman I, Borsook D. Psychological processing in chronic pain: a neural systems approach. Neurosci Biobehav Rev. 2014; 39:61-78.

26. Hawkley LC, Cacioppo JT. Loneliness matters: a theoretical and empirical review of consequences and mechanisms. Ann Behav Med. 2010; 40:218-227.

27. Kidd BL, Urban LA. Mechanisms of inflammatory pain. $\mathrm{Br}$ J Anaesth. 2001; 87:3-11.

28. Victor C, Grenade L, Boldy D. Measuring loneliness in later life: a comparison of differing measures. Rev Clin Gerontol. 2005; 15:63-70.

29. Zhong BL, Li HJ, Zhu JH, Chen HH. Depression, anxiety and insomnia among methadone maintenance treatment outpatients: detection rates,comorbidity and correlates. Chin J Drug Depend. 2010; 19:371-375.

30. Yang Y, Xu Y, Chen W, Zhu J, Lu J, Zhong B. Loneliness and its impact on quality of life in Chinese heroindependent patients receiving methadone maintenance treatment. Oncotarget. 2017; 8:79803-79808. https://doi. org/10.18632/oncotarget.19565.

31. Mittendorfer-Rutz E, Dorner TE. Socio-economic factors associated with the 1year prevalence of severe pain and pain-related sickness absence in the Austrian population. Wiener klinische Wochenschrift. 2017.
32. Genebra C, Maciel NM, Bento TPF, Simeao S, Vitta A. Prevalence and factors associated with neck pain: a population-based study. Braz J Phys Ther. 2017; 21: 274-280.

33. Fernandez-de-las-Penas C, Hernandez-Barrera V, AlonsoBlanco C, Palacios-Cena D, Carrasco-Garrido P, JimenezSanchez S, Jimenez-Garcia R. Prevalence of neck and low back pain in community-dwelling adults in Spain: a population-based national study. Spine. 2011; 36:E213-219.

34. Baldini A, Von Korff M, Lin EH. A Review of Potential Adverse Effects of Long-Term Opioid Therapy: A Practitioner's Guide. Prim Care Companion CNS Disord. 2012; 14.

35. Voon P, Callon C, Nguyen P, Dobrer S, Montaner J, Wood E, Kerr T. Self-management of pain among people who inject drugs in Vancouver. Pain Manag. 2014; 4:27-35.

36. Nelson DA, Menzel N, Horoho P. Prior depression and incident back pain among military registered nurses: A retrospective cohort study. Int J Nurs Stud. 2017; 74: 149-154.

37. Wang XD, Wang XL, Ma H. Handbook of Mental Health Rating Scales. (Beijing: Chinese Mental Health Journal Press). 1999.

38. Zhong B, Xu Y, Jin D, Zou X, Liu T. Prevalence and correlates of loneliness among Chinese service industry migrant workers: A cross-sectional survey. Medicine. 2016; 95:e3903.

39. Dahlberg L, Andersson L, McKee KJ, Lennartsson C. Predictors of loneliness among older women and men in Sweden: A national longitudinal study. Aging Ment Health. 2015; 19:409-417.

40. Routasalo PE, Savikko N, Tilvis RS, Strandberg TE, Pitkala KH. Social contacts and their relationship to loneliness among aged people - a population-based study. Gerontology. 2006; 52:181-187.

41. Yang K, Victor C. The prevalence of and risk factors for loneliness among older people in China. Ageing Soc. 2008; 28:305-327.

42. Pinquart M, Sorensen S. Influences on Loneliness in Older Adults: A Meta-Analysis. Basic Appl Soc Psych. 2001; 23:245-266.

43. Luo Y, Waite LJ. Loneliness and mortality among older adults in China. J Gerontol B Psychol Sci Soc Sci. 2014; 69:633-645.

44. Ferreira-Valente MA, Pais-Ribeiro JL, Jensen MP. Validity of four pain intensity rating scales. Pain. 2011; 152:2399-2404.

45. Li CR, Zhang W, Fan BF. A comparison between numberic rating scale (NRS) and verbal rating scale (VRS) in elderly patients with chronic pain. Chin J Pain Med. 2016; 22:683-686. 